\title{
Radio Communication in the British Navy.
}

THE history of the development of radio communication in the British Navy is of great interest. From a paper on "Naval Wireless Telegraph Communications", by G. Shearing and Captain Dorling, which was read to the Institution of Electrical Engineers on Dec. 4, we learn that Admiral Jackson experimented with radio waves so far back as 1896 . In 1899, with the help of Marchese Marconi, ranges up to 50 miles were obtained. In 1909 a crystal detector was first used, and in 1914, immediately prior to the War, valve reception was passing out of the experimental stage. During the War, arc and spark systems were generally used, but the thermionic valve system soon made them obsolete. The six months' cruise of H.M.S. Renown in 1927 provided opportunities for testing the capabilities of short-wave working on long ranges. With the exception of three days, communication was easily maintained with Whitehall.

The British Navy is divided up into squadrons, which are normally situated in distant seas under the orders of a Commander-in-Chief. There are squadrons, for example, in China, the East Indies, Africa, America, and the West Indies. Each naval area has one or more land radio stations which act as terminal points for the traffic to and from the Admiralty and as distributing and collecting centres for ships in the vicinity. If no commercial stations are available the naval stations are also used for communicating with merchantmen. They have a range varying from 1000 to 2000 miles and can also be linked up with the cable and land-line systems. The advent of the short-wave system has now made it possible for ships in any part of the world to communicate directly with each other and with the Admiralty at certain times of the day.

To obtain the results given above, H.M. ships of the cruiser class are fitted with a 12-kilowatt transmitter for long waves and an 8-kilowatt transmitter for short waves. Valve transmitters are always used. The long-wave apparatus has a range of about 1500 miles. In addition, they have two or three sets of receiving apparatus for long and short waves, besides direction-finding sets and fire-control radio sets. All the standard apparatus used is robust and simple to handle. It is proof against vibration and shocks from gunfire and has to be trustworthy under all climatic conditions. In the battle fleet, the commander must be able to transmit his orders to any unit of the force and be in touch with the Admiralty at the same time.

The striking feature of a modern fleet action is the speed at which everything happens. If the two fleets are approaching one another at a speed of between 40 and 50 miles an hour, then even with aircraft reconnaissance the time between first sighting the enemy and joining action may be only about an hour. The valve transmitters used after the War generally used frequencies between 60 and 3000 kilocycles, that is, wave-lengths between 5000 metres and 100 metres. The introduction of short waves, however, has modified the requirements very considerably. Their advantages for long range working at distances from a few hundred miles up to world-wide range during certain hours of the day are well known. It has been necessary, therefore, to arrange for the fitting of attachments to the existing sets capable of transmitting on a band of waves from 4300 to 21,500 kilocycles in breadth (wave-lengths of 70 metres to 14 metres).

\section{Antarctic Meteorology.}

ATER considerable delay, due principally to lack of funds, it was found possible in 1923 to undertake the tabulation and reduction of the several series of meteorological observations taken by the Australasian Antarctic Expedition of 1911-14. The first two (Series B, Vols. 3 and 4) of four contemplated volumes are now published.1. Another volume is to deal with the records taken during a winter at Queen Mary Land and the observations made on the aurora during the antarctic and sub-antarctic courses, and the last will contain a discussion of the figures.

The Macquarie Island station functioned after the return of Sir Douglas Mawson's Expedition, but owing to War conditions was closed down in December 1915. It has not since been found possible to reopen it. The monotony of the climate does not suggest that very important data would be obtained from its continuance, however valuable it might be in forecasting. Temperature ranged within a few degrees of $40^{\circ} \mathrm{F}$.; precipitation occurs on most days in the year and strong westerly or north-westerly winds prevail. The rainfall records are not so complete as the other data, which are very full.

Vol. 4 covers a period of $22 \frac{1}{2}$ months at Cape Denison on Commonwealth Bay, the headquarters of the expedition. These data are most important in their contribution to the study of the antarctic

1 Australasian Antarctic Expedition, 1911-14. Scientific Reports. Series B, Vol. 3: Meteorology. Tabulated and Reduced Records of the Macquarie Island Station. Recorders: G. F. Ainsworth, H. Power and A. C. Tulloch. Reduction and Tabulation of Data, by Direction of H. A. Hunt, and under Superintendence of B. W. Newman Pp. 544+4 plates. 40s. Voí. 4: Meteorology. Tabulated and Reduced Records of the Cape Denison Station, Adélie Land. By C. T. Madigan; with an Appendix by W. E. Bassett. Pp. $286+$ viii +2 plates. 30s. (Sydney : Alfred James Kent, 1929.) climate and particularly to the well-known antarctic blizzards. Sir Douglas Mawson chose a thoroughly uncomfortable but most valuable site for his station. He arranged for all observations to be taken every six hours, except during the latter part of the second year, when the screen thermometer was read only once a day. In addition to the detailed tables, the meteorological journal of the expedition is printed.

Mr. Madigan rightly says that the wind is the outstanding characteristic of Adélie Land. So far as records go, Commonwealth Bay would appear to be the windiest place on earth. The mean hourly wind velocity for the whole period of 22 months was $44 \cdot 2$ miles per hour. It may be recalled that 43 miles per hour is a gale on the Beaufort scale. In February 1912, which was the calmest month, the average velocity was 26.2 miles per hour. Wind velocities were taken with a Robinson cup anemometer, except for short periods when they were visual owing to the instrument being damaged by the wind.

The wind blew mainly from the south-south-east and south and was generally very steady, so that after some practice the explorers abandoned crawling and walked on their feet in 90-mile currents of air, leaning on the wind. There were occasional periods of calm and variable winds, but these were apparently local, for the wind could frequently be heard roaring on the plateau to the south, and to the west of the station drift snow could be seen sweeping down to the sea. Local whirlwinds from the north sometimes interrupted the short calms.

Mr. Madigan does not discuss the antarctic atmosphere circulation, but we hope he will do so in the final volume of the series. 